\title{
JBJS Reports on the Latest in Spine
}

\section{-L. Uzdienski}

In July 2009, JBJS published a review entitled "What's New in Spine Surgery." We've summarized some of the highlights below.

\section{POSITIVE OUTCOMES FOR CERVICAL DISC ARTHROPLASTY}

In two recent studies, arthroplasty was associated with equal or greater pain relief and functional outcomes when compared to fusion and discectomy. Adverse events were similar in both groups, with fewer reoperations in the arthroplasty group. Satisfactory outcomes were maintained at four years in both the arthroplasty and fusion groups.

\section{BIOLOGICS SHOW PROMISE, BUT DEVELOPMENT IS SLOW}

- BMPs: Results have been "inconsistent" in studies of DePuy's GDF-5. BMP-7 (Stryker's OP-1) is reportedly still under review by the FDA, and it has been suggested that the current concentration of the BMP may be insufficient for spinal fusion. BMP-2 (Medtronic's Infuse) has performed well in studies, but concerns remain about adverse events, particularly in the cervical spine.
- Bone graft substitutes: Mesenchymal stem cells remain an area of interest, though the amount of cells needed to elicit a bonehealing response as well as what triggers need to be expressed by the cells is unknown. - Disc degeneration: biologic treatments in this space are developing at a "slow pace," though a human trial evaluating BMP delivery to discs to prevent degeneration is in development.

\section{NEW TECHNOLOGIES, NEW PATIENTS FOR LUMBAR SPINE PROCEDURES}

- SPORT: Compared to nonsurgical treatment, surgical treatment resulted in better outcomes for all patients in the study. Compared to patients with primary back pain, patients with primary leg pain improved more with surgical treatment.

- Surgery in the elderly: Higher complication rates are observed in this population, though one recent study demonstrated the "substantial benefits" associated with fusion in this group.
- New technology: In one study comparing Zimmer's Dynesys, a pedicle-based dynamic stabilization system, with lumbar posterolateral fusion, the dynamic stabilization group reported a greater improvement in leg pain and back pain scores when compared to fusion, though overall results in both groups were comparable. A separate study evaluating Dynesys found that $20 \%$ of patients receiving the device required re-operation at two years. $39 \%$ of these cases were attributable to screw loosening, with additional complications including screw breakage and cephalad spinal stenosis •

This report is reproduced by kind permission of the author and of our partner, HealthpointCapital. It was previously published in July 2009 on the website: www.healthpoincapital.com

DOI: 10.1007/s12240-009-0034-y

\section{Book Review by Pierre Kehr}

\section{Dynamic Reconstruction of the Spine \\ Daniel H. Kim, Daniel H., Frank P. Calisa, Richard G. Fessler [Eds] \\ by JP. Steib}

n our knowledge this is the first book dedicated to non-fusion and motion preservation of the spine. The two mobile areas are concerned, cervical and lumbar. Experienced surgeons well known for their practice treat each system or philosophy with many explanations and details on the technique. The contents is complete: restoration of cervical motion segment, restoration of lumbar motion segment by lumbar nucleus or total disk replacement, dynamic posterior stabilization by interspinous process spacers or pedicle screw-based systems, facet replacement, annular repair and even future biological approaches to disk repair. This book is complete and up-to-date even if this part of surgery is every day in evolution. This book has its place on the shelves of every spine surgeon to learn, to teach and simply to stay in touch with the future of his specialty.
This book review was previously published : Eur J Orthop Surg Traumatol (2007) 17:625-630. DOI: 10.1007/s00590-007-0239-8

/+/ Dynamic Reconstruction of the Spine

Daniel H. Kim, Daniel H., Frank P. Calisa, Richard G. Fessler (Eds) 2006, 510 p.; 560 figs.; Hardcover. Euro (D) 159,95 CHF 253,00. Thieme Verlag New York, Stuttgart. ISBN: 3-13-142681-0

\section{Complications of Spine Surgery, Treatment and Prevention \\ Howard S. An, Louis G. Jenis [Eds.] \\ by JP. Steib}

t was a wonderful idea to write a book dedicated to complications of spine surgery. This surgery is very particular including so many different aspects of the anatomy and involving so many specialities of surgery. 40 contributors work to this book to describe the specific complications of the cervical, thoracic and lumbar spine. Unfortunately the result is not so high we could dream it. It's more an overview than a real description fashion dictionary, the presentation is not didactic, the drawings are not enough numerous and their quality is poor without any color. It's difficult for a technical book to deal with the complication after the lecture. Tricks, personal experience and recommendations are missing in front of a review of the literature. This book was coming from a good intention but is disappointing.

This book review was previously publsihed in Eur $\mathrm{J}$ Orthop Surg Traumatol (2007) 17:425-429. DOl: 10.1007/s00590-006-0184-y

\section{/+/ Complications of Spine Surgery,}

Treatment and Prevention Howard S. An, Louis G. Jenis (Eds.) 10/2005 - 235 pp. - 139,00 US\$. Lippincott Williams\& Wilkins a Wolters Kluver Company. Philadelphia - Baltimore New York - London - Buenos Aires - Hong Kong Sydney - Tokyo. ISBN 0-7817-5791-6

ERRATUM In the September 2009 issue (Volume 21, Number 3) the names of the authors of the article: "EOS a new 2D/3D, low dose musculoskeletal imaging system" were mispelled. The correct spelling of their names is : Ibrahim Obeid and Tamas Illes.

DOI: $10.1007 /$ s12240-009-0037-8 